\title{
TERRITORIALIDADE, SOBERANIA E CONSTITUIÇÃO: AS BASES INSTITUCIONAIS DO MODELO DE ESTADO TERRITORIAL SOBERANO
}

TERRITORIALITY, SOVEREIGNTY AND CONSTITUTION: THE INSTITUTIONAL BASIS OF THE MODEL OF "SOVEREIGN TERRITORIAL STATE"

TERRITORIALIDAD, SOBERANIÁA Y CONSTITUCIÓN: LAS BASES INSTITUCIONALES DEL MODELO DE ESTADO TERRITORIAL SOBERANO

Luiz Magno Pinto Bastos Júnior ${ }^{12}$

Resumo: O objetivo deste artigo consiste em identificar um conjunto de elementos constitutivos do chamado modelo de "estado territorial soberano" que serviu de base para a consolidação do estado moderno e, por conseguinte, da própria teoria constitucional. Estes elementos constitutivos permitem a identificação das bases institucionais sobre as quais se erigiu o

1 Mestre e Doutor em Direito Público pela Universidade Federal de Santa Catarina (UFSC). Professor de Direito Constitucional e Direito Processual Constitucional da Universidade do Vale do Itajaí, na graduação (Direito e Relações Internacionais) e pós-graduação (Programa de Mestrado e Doutorado em Ciência Jurídica). Advogado e sócio do Escritório Menezes Niebuhr Advogados Associados. E-mail: Imagno@univali.br; Imagno@mnadvocacia.com.br.

2 Pesquisa financiada com recursos do CNPq (Projeto 486144/2011-9, Edital Universal 14/2011). 
Estado moderno e os elementos que compõem a matriz operativa a partir da qual, desde então, se estrutura a forma de ordenação do político na modernidade. Desta forma, o modelo aqui identificado de "estado territorial soberano" será tratado como princípio organizativo e será decomposto em quatro dimensões distintas (autoridade, princípio organizativo, fundamento de legitimidade e critério para construção de identidades) que servirão de fio condutor para a compreensão das transformações experimentadas no processo de consolidação desse modelo de organização da comunidade política e dos seus influxos no desenvolvimento do conceito de soberania.

Palavras-chave: Territorialidade. Soberania. "Estado territorial soberano".

Abstract: This article aims to identify the elements that comprise the model of "sovereign territorial state", which serve as the basis of the consolidation of the modern state, and therefore, of constitutional theory itself. These elements allow the identification of the institutional foundations upon which the modern State was built, and the elements that compound the operational matrix that structures the ordering of the political dimension in modernity. Thus, the model identified (sovereign territorial state) is seen as an ordering principle, and will be broken down into four different dimensions (authority, ordering principle, basis of legitimacy, and criteria for the construction of identities) that will be used as parameter for understanding the transformations taking place in the process of consolidation of this model of organization of the political community, and its influences on the development of the concept of sovereignty.

Key-words: Territoriality. Sovereignty. Sovereign territorial state. 
Resumen: El objetivo de este artículo consiste en identificar un conjunto de elementos constitutivos del denominado modelo de "estado territorial soberano" que sirvió de base para la consolidación del estado moderno y, por consiguiente, de la propia teoría constitucional. Estos elementos constitutivos permiten la identificación de las bases institucionales sobre las cuales se erigió el Estado moderno y los elementos que componen la matriz operativa a partir de la cual se estructura desde entonces la forma de ordenación de lo político en la modernidad. De esta manera, el modelo aquí identificado de "estado territorial soberano" será tratado como principio organizativo y será descompuesto en cuatro dimensiones distintas (autoridad, principio organizativo, fundamento de legitimidad y criterio para la construcción de identidades) que servirán de hilo conductor para la comprensión de las transformaciones sufridas en el proceso de consolidación de ese modelo de organización de la comunidad política y de sus influjos en el desarrollo del concepto de soberanía.

Palabras clave: Territorialidad. Soberanía. "Estado territorial soberano".

\section{INTRODUÇÃO}

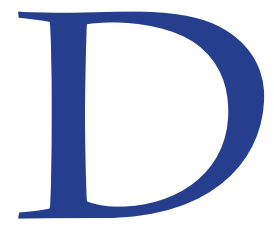

urante o longo processo de consolidação do Estado moderno, a "ideia de constituição", progressivamente, passa a ocupar um lugar central tanto para o direito, quanto para a ciência política. Esse "sucesso" vem sendo constantemente ressaltado independentemente da perspectiva que se adote. Do ponto de vista das ideias políticas, a constituição passa a ser considerada uma "escritura necessária do poder"; do ponto de vista do direito, é com a ideia de supremacia constitucional que se torna possível compreender o direito como unidade sistemática dotada de um único ponto de imputação; ainda, sob a perspectiva da intersecção entre direito e política, a novidade moderna da constituição decorre do fato de atuar como ponto de ligação estrutural entre direito e política. 
A importância atribuída à "ideia de constituição", como parte integrante dos modelos de organização do político e como fator de legitimação dos discursos sobre o poder, não ocorreu sem que o vocábulo constituição sofresse um processo de profunda transformação semântica: de instrumento de conservação das forças constitutivas dos extratos sociais (atrelado à noção de "constituição mista" do medievo) a instrumento de transformação social da comunidade política revestido de pretensão de normatividade.

No âmbito dos estudos sobre história das ideias políticas, este conjunto de transformações costuma ser associado a uma categoria analítica, o constitucionalismo3 ${ }^{3}$ a partir da qual são selecionados múltiplos elementos e aspectos particulares da experiência política, que permitiram reconstruir (criativamente) as tramas das narrativas em torno das técnicas de limitação do exercício do poder tendo em vista a demarcação de um espaço de liberdade ineliminável dos cidadãos.

Muito embora os discursos sobre a constituição sejam contemporâneos à sedimentação das bases institucionais do estado moderno, o surgimento da teoria constitucional com pretensão de cientificidade e como disciplina que pretende tratar a constituição como problema autônomo data do primeiro quartel do século XX. E, como tal, representa uma resposta ao cenário de crise experimentado pelo ideal liberal de Estado e de direito, levado a efeito pelo efervescente período de entreguerras do constitucionalismo de Weimar.

O objetivo deste artigo consiste em identificar um conjunto de elementos constitutivos do chamado modelo de "estado territorial soberano" que serviu de base para a consolidação do estado moderno e, por conseguinte, da própria teoria constitucional. A identficiação destes elementos constitutivos permite a identificação das bases institucionais sobre as quais se erigiu o Estado moderno e os elementos que compõem a matriz operativa a partir da qual, desde então, se estrutura a forma de ordenação do político na modernidade.

3 A expressão constitucionalismo costuma ser utilizada em dois sentidos distintos, ora como um esforço de reconstrução histórica acerca do desenvolvimento das ideias políticas e dos mecanismos institucionais de limitação do exercício do poder; ora como uma ideologia mediante a qual se formulam teorias normativas de feição valorativa e prescritiva sobre a melhor forma de organização política. 
Desta forma, o modelo aqui identificado de "estado territorial soberano" será tratado como princípio organizativo e será decomposto em quatro dimensões distintas (autoridade, princípio organizativo, fundamento de legitimidade e critério para construção de identidades) que servirão de fio condutor para a compreensão das transformações experimentadas no processo de consolidação desse modelo de organização da comunidade política e dos seus influxos no desenvolvimento do conceito de soberania.

Ao final, defende-se que este esforço de compreensão do papel estruturante que a associação entre autoridade e território desempenhou no processo de institucionalização do Estado fornece importantes chaves de leitura para a compreensão de diferentes movimentos contemporâneos de desterritorialização da autoridade (e, por conseguinte, do direito e da constituição).

A noção de "estado territorial soberano" como estrutura organizacional básica do Estado moderno

Nos termos assumidos por este trabalho, o edifício do Estado moderno erigese sobre um verdadeiro acoplamento da autoridade pública à noção de território. Esta relação se constitui na exata medida em que a legitimidade do exercício da autoridade pública se institucionaliza em bases territoriais, ou seja, o espaço territorial do Estado passa a ser a referência para a demarcação dos âmbitos de validade 4 do ordenamento jurídico estatal. O modelo operativo de Estado moderno traduz-se, portanto, na noção de estado territorial soberano ${ }^{5}$.

O desenvolvimento do estado territorial como modelo resultou da consolidação da noção de governo central, ou seja, de um agrupamento dos distintos domínios semifeudais de governo em um único quadro institucional de autoridade pública ${ }^{6}$.

4 De acordo com Hans Kelsen, os âmbitos de validade são as projeções materiais das condições de significação normativas sobre o ser. Existem quatro âmbitos de validade em Kelsen: material, formal, pessoal e temporal-espacial. (KELSEN, Hans. Teoria pura do direito. 6.ed. São Paulo: Martins Fontes, 1998).

5 Cf. GOYARD-FABRE, Simone. Os princípios filosóficos do direito político moderno. São Paulo: Martins Fontes, 1999, pp. 55-110; CASELLA, Paulo Borba. Direito internacional dos espaços. São Paulo: Atlas, 2009, pp. 20-21; ESTEVES, Paulo. Para uma genealogia do Estado territorial soberano. Revista de Sociologia e Política, Curitiba, n. 27, p. 15-32, nov. 2006.

6 CAPORASO, James. Changes in the Westphalian order: territory, public authority, and sovereignity. In: (Org.). Continuity and change in the Westphalian order. Malden, USA; Oxford, UK: Blackwell Publishers, 2000, p. 22. 
Esta "novidade" moderna é tão significativa que Daniel Philpot” refere-se a ela como uma das mais significativas "revoluções" na evolução da ideia de soberania. $\mathrm{E}$, de forma ainda mais enfática, John Ruggie defende que a característica marcante do moderno sistema de governo territorial consiste justamente na consolidação de toda autoridade (antes fragmentada/compartimentada e personalizada) em torno de um domínio público, domínio este construído no interior de autênticos enclaves territoriais (bem delineados, fixos e mutuamente excludentes) ${ }^{8}$. Resta, pois, discutir brevemente como se deu esse processo de transformação e desenvolvimento de suas bases institucionais.

O processo de consolidação do "modelo de estado territorial" operou, na definição de James Caporaso, uma autêntica "virada vestfaliana"9. Esta guinada organizacional importou na redefinição das estruturas de poder do medievo tendo por referência a unidade territorial do Estado-nação.

Apesar do reconhecimento de múltiplos elementos constitutivos, a tradição consolidada no âmbito da filosofia e ciência políticas refere-se à soberania como um conceito monolítico, como um atributo dos Estados que deva ser aferido em critérios absolutos: ou o Estado detém a soberania, ou não é um Estado. É bem verdade que a definição da soberania em termos absolutos encontrou inúmeras dificuldades operacionais para lidar com realidades como a Cidade-Estado do Vaticano ou a situação da China insular (Taiwan). Diante destas situações-limite, a incapacidade da teoria de lidar com estes arranjos institucionais atípicos tende a ser minimizada pelo recurso a existência de situações sui generis que somente confirmariam a regra de que a soberania em termos formalmente absolutos é um traço distintivo (e constituivo) do Estado.

No entanto, a compreensão da soberania em termos absolutos não tem sido capaz de conferir sentido à existência concreta de instâncias decisórias para além do Estado-nação. Estas searas que concorrem com a autoridade do Estado (e cuja

$7 \quad$ PHILPOT, Daniel. Revolutions in sovereignty: how ideas shapped modern international relations. Princenton, Princenton University Press, 2001.

8 RUGGIE, John Gerard. Territoriality and beyond: problematizing modernity in international relations. International organization, Cambridge Journals, v. 47, n. 1, p. 139-174, Winter, 1993, p. 151.

9 CAPORASO, James. Changes in the Westphalian order: territory, public authority, and sovereignity. pp. 1-28. 
legitimidade, em grande medida, constroem-se a partir dos próprios Estados) têm comprimido sua autonomia, o que exige que o conceito de soberania seja compreendido em termos relativos.

Frequentes têm sido os esforços de decomposição da noção de soberania em múltiplos elementos, alguns dos quais seriam mantidos sob o domínio das instituições-padrão dos Estados nacionais. Neste setntido, Stephan Kranser fala da existência de "concepções parciais de soberania"10, Neil MacCormick propõe a necessidade de se compreender a existência de graus diferenciados de exercício de poderes soberanos ${ }^{11}$ e, ainda, a partir de uma perscpectiva realista, Karen Litfin defende a ocorrência de uma espécie de negociação da soberania (sovereignty bargains) como parte da estratégia dos Estados em manter ao menos alguns de seus atributos soberanos ${ }^{12}$.

Neste trabalho, defende-se que a ideia de soberania foi desenvolvida a par do processo de construção artificial de identidades nacionais e de que a decomposição de seus elementos constitutivos permite compreender este processo.

Os elementos assumidos seguem, em linhas gerais, aquilo que James Caporaso $^{13}$ definiu como dimensões da soberania e podem ser sintetizados no Quadro 1:

Quadro 1: Dimensões da organização política e os problemas relacionados

\begin{tabular}{|l|l|l|}
\hline Dimensões & Questões relacionadas & Problema \\
\hline $\begin{array}{l}\text { Autoridade (poder de } \\
\text { decisão) }\end{array}$ & $\begin{array}{l}\text { Capacidade de decidir e de fixar } \\
\text { regras sobre conflitos }\end{array}$ & $\begin{array}{l}\text { Quem decide em última } \\
\text { instância? }\end{array}$ \\
\hline Princípio organizativo & $\begin{array}{l}\text { Forma de organização do político } \\
\text { (critério de demarcação de } \\
\text { jurisdição) }\end{array}$ & $\begin{array}{l}\text { Qual é a melhor forma de } \\
\text { organização? }\end{array}$ \\
\hline
\end{tabular}

10 KRASNER, Stephan. Sharing sovereignty: new institutions for collapsed and failing states. International security, v. 29, n. 2, p. 85-120, fall 2004.

11 MACCORMICK, Neil. Questioning sovereignty: law, state, and practical reason. Oxford: Oxford University Press, 1999.

12 LITFIN, Karen T. Sovereignty in world ecopolitics. Mershon International Studies Review, The International Studies Association, v. 41, n. 2, p. 167-204, nov. 1997.

13 CAPORASO, James. Changes in the Westphalian order: territory, public authority, and sovereignity. pp. 1-28. 


\begin{tabular}{|l|l|l|}
\hline Fundamento de legitimidade & $\begin{array}{l}\text { O "direito de governar" e o } \\
\text { "reconhecimento do direito" de } \\
\text { governar }\end{array}$ & $\begin{array}{l}\text { Qual é o fundamento do } \\
\text { exercício de um governo } \\
\text { legítimo? }\end{array}$ \\
\hline Construção de identidades & $\begin{array}{l}\text { Os fatores de integração e e } \\
\text { de construção dos vínculos é o fator que } \\
\text { comunais }\end{array}$ & $\begin{array}{l}\text { contribuipara integração } \\
\text { comunitária? }\end{array}$ \\
\hline
\end{tabular}

De acordo com o autor, a primeira dimensão diz respeito à ideia de autoridade (enquanto poder de decisão). A questão da autoridade associa-se diretamente com o problema da decisão, ou seja, com a discussão sobre a capacidade do soberano de emitir decisões e de emitir regras sobre os conflitos por ventura existentes entre decisões que, tomadas a partir de seus critérios próprios de legitimidade, revelarse-iam igualmente legítimas. Em princípio, a coexistência de diferentes estruturas de autoridade em um mesmo espaço de atuação, sem que entrem em rota de colisão, não suscita nenhum problema à soberania, do contrário, a existência de estruturas de autoridade não pressupõe a existência de soberania.

A soberania entra em cena quando se coloca em questão o problema da autoridade suprema; portanto, quando se estabelece algum critério de hierarquização de autoridades, quando são veiculadas metanormas para solução dos conflitos. Portanto, a existência de critérios (e autoridades) capazes de resolver a tensão potencial entre instâncias decisórias é o principal traço distintivo do atributo de "soberania" como capacidade de decisão.

A segunda dimensão refere-se ao princípio organizativo do espaço político, em especial, em relação aos princípios subjacentes à forma com que o espaço político é organizado e a forma como atuam e são articuladas as autoridades e os atores políticos. O princípio organizativo fixa o critério básico estruturador do enfeixamento de autoridades, tanto no sentido de fixação de competências, quanto no sentido de delimitação dos âmbitos de validade da atuação da autoridade pública.

No estado territorial soberano, a organização política é territorial, ou seja, o alcance normativo da autoridade pública circunscreve-se ao interior de determinadas espaços geograficamente delimitados. 
A terceira dimensão diz respeito ao fundamento de legitimidade. Esta dimensão enfrenta o problema da legitimidade do exercício do poder, ou seja, a questão referente àquele que detém o "direito de governar" e o correlato "reconhecimento desta prerrogativa".

O enfrentamento deste problema é uma das questões fulcrais à filosofia política, desde a Antiguidade. No momento de afirmação do modelo de "estado territorial soberano", a questão em torno da legitimidade dessubstancializa-se (deslocando-se da busca por critérios universais de legitimidade). Isto é possível graças à ênfase atribuída pela filosofia política moderna, no aspecto procedimental do exercício do poder e na busca da definição de mecanismos institucionais de controle do desvio de seu exercício.

Por fim, a quarta dimensão, que neste trabalho ${ }^{14}$ será associada à construção de identidades. Sua ideia-motriz decorre do reconhecimento de que qualquer grupamento pressupõe a fixação de vínculos de identidade entre seus membros que os distinguem daqueles que lhe são estranhos (do seu outro).

No estado territorial soberano, é o atributo da cidadania que irá diferenciar o nacional do estrangeiro e que irá vincular aquele ao estado nacional, reconhecendo-Ihe direitos e imputando-Ihe responsabilidades. A relação de pertencimento do indivíduo ao estado nacional tradicionalmente serve como o ponto de partida para a compreensão de cidadania. Ademais, foi justamente com base neste elo formal entre Estado e cidadão que foi possível forjar a concepção moderna de Nação como "comunidade política de destino". Trata-se de uma construção artificial que, fixada com base na demarcação de um elemento contingente (a fronteira), pretende uma espécie de homogeneização interna mediante o cultivo do passado (mitos sobre as origens do povo) e a promoção de elementos compartilhados (língua, etnia e religião).

A identificação destas dimensões da soberania não permite, por si só, nem definir como se deu o processo de sua afirmação, nem compreender o papel organizativo desempenhado pelo "princípio da territorialidade", questão enfrentada na próxima seção.

14 Esta dimensão não foi expressamente enfrentada por James Caporaso, representando uma proposta subscrita pelo autor deste artigo. 
A "territorialidade" como unidade estruturante da "virada vestfaliana" na forma de organização social

Como dito anteriormente, o processo de consolidação do estado territorial soberano operou-se por meio daquilo que foi denominado como "virada vestfaliana". Esta guinada materializa-se pela afirmação do princípio de territorialidade, em outras palavras, com a fixação do elemento territorial como unidade básica para as estruturas de autoridade. "Quando o princípio territorial emerge, ele imediatamente traz à tona a questão da ordenação do espaço, independentemente das questões de fundo veiculadas"15. O estado territorial é, por óbvio, um estado com fronteiras físicas e com um senso bem desenvolvido das relações dentro/fora e nós/eles ${ }^{16}$.

Tomando por base as quatro dimensões antes destacadas, este processo pode ser sumarizado por meio do Quadro 2.

Quadro 2: Dimensões da virada vestfaliana (westphalian turn)

\begin{tabular}{|c|c|c|}
\hline Dimensões & $\begin{array}{l}\text { Organização Política do } \\
\text { Medievo }\end{array}$ & $\begin{array}{l}\text { Estado Territorial } \\
\text { Soberano }\end{array}$ \\
\hline $\begin{array}{l}\text { Autoridade } \\
\text { (poder de decisão) }\end{array}$ & $\begin{array}{l}\text { Dispersa em âmbitos } \\
\text { distintos sobrepostos }\end{array}$ & $\begin{array}{l}\text { Consolidada } \\
\text { (centralizada } \\
\text { hierarquicamente) }\end{array}$ \\
\hline Princípio organizativo & $\begin{array}{l}\text { Forma de organização } \\
\text { a-espacial }\end{array}$ & $\begin{array}{l}\text { Forma de organização } \\
\text { espacial (territorial) }\end{array}$ \\
\hline Fundamento de legitimidade & Personalização e Sacralização & $\begin{array}{l}\text { Racionalização } \\
\text { (institucionalização) }\end{array}$ \\
\hline Construção de identidades & $\begin{array}{l}\text { Organização local + } \\
\text { vínculos de pertencimento à } \\
\text { Cristandade }\end{array}$ & $\begin{array}{l}\text { Identidade nacional } \\
\text { (cidadania) }\end{array}$ \\
\hline
\end{tabular}

15 CAPORASO, James. Changes in the Westphalian order: territory, public authority, and sovereignity. p. 10.

16 David Blaney e Naem Inayatullah retratam a dificuldade (impossibilidade) que as relações internacionais, consolidadas com base no Sistema de Estados de matiz vestfaliana, têm que lidar com o "outro", tendo em vista o caráter demarcatório que a diferenciação nós-eles opera a partir da metáfora recorrente das fronteiras e da ideia excludente de cidadania. (Cf. BLANEY, David; INAYATULLAH, Naeem. The Westphalian deferral. In: CAPORASO, J (Org.). Continuity and change in the Westphalian order. Malden, USA; Oxford, UK: Blackwell Publishers, 2000. p. 29-64). 
Em relação à dimensão da autoridade, a insurgência de um governo único sobre um determinado território subverte a lógica de estruturas de múltiplas autoridades que reivindicam o exercício de sua autoridade a partir de diferentes fundamentos (costume, relações de confiança, natureza espiritual).

A estrutura de regulação do medievo era muito complexa e caracterizava-se por um "emaranhado de ordens sobrepostas", de forma que, em um mesmo espaço geográfico, coexistiam "diferentes instâncias jurídicas entremeadas e estratificadas, e abundavam situações de múltiplas sujeições, relações assimétricas de suserania e autênticos enclaves anômalos." ${ }^{17}$. A pluralidade de autoridades cede lugar à fixação de uma cadeia hierárquica de organização, em meio à qual emerge o soberano como o legítimo garantidor da ordem instituída.

Em relação à segunda dimensão, coexistia uma profusão de ordens que se estruturavam a partir de critérios outros que não a fixação em determinada base territorial, quer seja de caráter pessoal (relações de suserania e vassalagem), de natureza espiritual (domínio religioso sobre inúmeras dimensões da vida privada dos fiéis), ou mesmo, de natureza mercantil (lex mercatoria).

Por sua vez, a partir de um progressivo processo de organização administrativa acoplado à estrutura de dominação territorial dos bispados ${ }^{18}$ e desenvolvido com base na sedimentação de um corpo intermédio real de administração da justiça, foram sendo consolidadas ilhas dispersas de autoridade em uma mesma cadeia hierárquica de organização. Afirma-se, desta forma, o traço distintivo fundamental característico do modelo de estado territorial soberano, qual seja: o reconhecimento de "um" governo sobre determinado espaço, aplicável a todos os sujeitos e a todas as relações econômicas e sociais confinados em seu interior.

17 BEAULAC, Stéphane. The Westphalian model in defining international law: challenging the myth. Australian Journal of Legal History, v. 8, n. 2, p. 181-213, 2004. p. 189.

18 A organização eclesiástica em bases territoriais e a atuação dos bispos em inúmeras questões como delegatários reais forneceram, de acordo com a análise de Bruce de Mesquita, as bases institucionais para a afirmação da territorialidade, própria do modelo vestfaliano. A interação entre o domínio régio e a atuação eclesiástica teve suas bases lançadas na Querela das Investiduras no início do século XII (finalizada com as concordatas de Worms e de Londres). Se esta contenda entre o poder temporal e eclesiástico termina com a afirmação do primado do Papado no tocante à nomeação das prelazias episcopais, no entanto, acabou por estabelecer uma espécie de "direito dominial régio" exercido em relação ao território de cada bispado. (Cf. MESQUITA, Bruce Bueno de. Popes, kings, and endogenous institutions: the Concordat of Wor$\mathrm{ms}$ and the origins of sovereignty. In: CAPORASO, J. (Org.). Continuity and change in the Westphalian order. Malden, USA; Oxford, UK: Blackwell Publishers, 2000. p. 93-118.) 
Por seu turno, no plano da legitimidade, a diferença é substancial. Ocorre um processo de progressiva dessacralização do domínio político, que não resultou em um processo de desteologização do direito público como adverte Carl Schmitt ${ }^{19}$. O desenvolvimento de uma racionalidade burocrática no âmbito da administração estatal, agora profissionalizada, representa uma guinada significativa no processo de racionalização dos discursos sobre o poder e de fornecimento de parâmetros para sua aceitabilidade por parte dos governados.

Por fim, em relação à construção de identidades, há uma mudança abrupta no processo de constituição de coletividades. No medievo, os vínculos comunitários eram marcados, de um lado, por uma relação de pertencimento a povoados e comunidades locais baseada em laços de solidariedade e de proximidade geográfica; de outro, pela existência de vínculos universais que, para além das particularidades locais, permitia o reconhecimento de uma relação de pertencimento a uma comunidade cristã universal (cristandade), cuja unidade era alicerçada e mantida pela Instituição do Papado.

Como antes salientado, o processo de transição paradigmática decorre justamente do processo de construção de identidades nacionais, o qual, pretendendo afastar a existência de qualquer autoridade que se impusesse de fora do corpo político nacional, passa a constituir-se pela construção de vínculos formais entre os indivíduos (cidadãos) e o Estado, então insurgente.

Assim, a edificação de fronteiras (físicas e simbólicas), no processo de afirmação do estado territorial soberano, possibilitou a demarcação da comunidade política de "fora para dentro", ao afirmar a autoridade última do Estado dentro dos seus domínios territoriais ${ }^{20}$. A demarcação do território, como se vê, é anterior à própria ideia de nacionalidade e evidencia que o confinamento em determinado espaço geográfico representou uma condição anterior aos demais laços modernos de vinculação comunitária (língua, religião, história compartilhada, fatores simbólicos de agregação, entre tantos).

Este modelo organizativo difundiu-se largamente não só na Europa, mas também em escala global ${ }^{21}$. Paolo Cuttitta chama a atenção para o fato de que,

19 SCHMITT, Carl. Teologia política. Belo Horizonte: Del Rey, 2006.

20 RUDOLPH, Christopher. Sovereignty and territorial borders in a global age. The Internatio-

nal Studies Review, Malden; Oxford, Blackwell Publishers, v. 7, n. 1, p. 1-20, 2005. p. 4.

21 Cf. SPRUYT, Henrik. The sovereignty state and its competitors. Princeton: Princeton University Press, 1994. 
enquanto a ideia de identidade entre nação e estado (ínsita aos desenvolvimentos do estado territorial) acabou sendo em certa medida flexibilizada com a criação de estados multinacionais, o princípio da territorialidade, por sua vez, permaneceu intocável, já que a titularidade sobre determinado território ainda figura como condição necessária para o reconhecimento de qualquer Estado ${ }^{22}$. Isto é, o Estado exerce sua jurisdição exclusiva sobre determinado território, o qual é definido geograficamente por "fronteirais rígidas e lineares".

Após a delimitação do alcance da expressão "estado territorial soberano" e do papel desempenhado pelas fronteiras (físicas e simbólicas), passe-se, pois, à etapa subsequente que consiste em compreender de que forma o conceito de soberania fornece as bases para o entrincheiramento das relações constitutivas da comunidade política no seio do espaço territorial nacional.

\section{A DEMARCAÇÃO DAS FRONTEIRAS JURÍDICAS DA SOBERANIA}

NACIONAL

Após identificar as bases da organização do Estado territorial e perscrutar os fundamentos do reconhecimento da soberania como capacidade de decidir do soberano, incumbe aqui apresentar a relação da transmudação, para o interior do discurso jurídico, da ideia de fronteira do próprio Direito.

Como visto, o princípio da territorialidade contribuiu decisivamente para a construção da identidade comunitária em bases nacionais (identificação entre cidadania e nacionalidade) e a veiculação de regras constitutivas do enfeixamento de autoridades (identificação entre Direito e Estado). Como corolário disto, portanto, puderam ser construídos inúmeros mecanismos de distribuição de competências entre órgãos governamentais e de controles institucionais (construídos a partir da ideia de freios e contrapesos).

Diferentemente do que pode parecer, à primeira vista, a ideia de unidade sistemática da ordemjurídica (nacional) nãoconduz, inexoravelmente, àconstituição

22 CUTTITTA, Paolo. Points and lines: a topography of borders in global space. Ephemera: theory and politics in organization. v. 6, n. 1, p. 27-39, 2006. p. 28. 
de estados totais ${ }^{23}$, ou mesmo na negação da diferença intracomunitária, ou mesmo, na errônea assunção de que o princípio da não contradição das normas jurídicas decorre de uma implicação lógica da própria noção de sistema.

O que a noção de "estado territorial soberano" permite inferir é que, independentemente da existência de limites à atuação do Estado em relação à sociedade, quando o conflito entre autoridades ocorrer, o Estado pode avocar a prerrogativa de poder ditar a palavra final ${ }^{24}$. Com isto, as fronteiras artificiais do Estado passam igualmente a demarcar seu espaço de autonomia em face do seu outro (a comunidade internacional em sua totalidade) ${ }^{25}$.

Opera-se, assim, no seio dos discursos de produção (e reprodução) do direito, uma espécie de demarcação espaço-temporal que confere sentido à realidade do Estado (ao passo que a identifica ao direito). Esta identidade lógica, ao remeter ao conceito teórico de soberania da ordem jurídica estatal,

(...) permite falar tanto na validade última da ordem jurídica como na soberania do Estado, no sentido de um processo de imputação normativa, no fim do qual se estabelecem as regras fundamentais do direito constitucional de um país. ${ }^{26}$

A decisão soberana instituinte de uma nova ordem jurídica converte-se, quando traduzida na linguagem jurídico-constitucional, na engenhosa formulação de Siéyès de "poder constituinte", um ato de força pura que, por sua efetividade, positiva em uma ordem jurídica que, somente como sistema jurídico, pode ser considerada soberana.

Seguindo o caminho percorrido por Ari Solon, sem coincidir com as conclusões finais a que chega ${ }^{27}$, é possível identificar no embate travado entre as posições 23 Neste sentido, avassaladora é a crítica de Hans Kelsen (O Estado como integração. São Paulo: Martins Fontes, 2003) e mesmo de Carl Schmitt (Teoría de la constitución. Trad. Francisco Ayala. México: Editora Nacional, 1970) contra a ideia de direito como integração constante da proposta, influente no período weimariano, de Rudolf Smend (Constitución y derecho constitucional. Madrid: Centro de Estudios Constitucionales, 1985).

24 CAPORASO, James. Changes in the Westphalian order: territory, public authority, and sovereignity. pp. 1-28.

25 Cf. WALKER, Rob. The double outside of the modern international. Ephemera: theory and politics in organization. v. 6, n. 1, p. 56-69, 2006.

26 SOLON, Ari Marcelo. Teoria da soberania como problema da norma jurídica e da decisão. Porto Alegre: SAFE, 1997, p. 199.

27 A principal objeção feita em relação à tese de Ari Solon consiste na questão central por ele 
antagônicas de Kelsen e Schmitt uma série de elementos comuns que, eliminando as posições extremadas que caracterizam a postura dos autores (soberania como norma e soberania como decisão), evidenciam dois aspectos de vital importância para a compreensão da operatividade da ideia de unidade sistemática do direito, contemporaneamente traduzida na percepção de uma dupla natureza do direito como faticidade e como validade. Esta dupla acepção decorre da inarredável referibilidade das normas jurídicas ao mundo do ser.

Passar a compreender a soberania a partir do reconhecimento desta ambivalência constitutiva, tanto como norma quanto como decisão, no âmbito interno, pressupõe o reconhecimento de uma tensão existencial entre a noção de supremacia ínsita à soberania nacional e a ideia reguladora de sua subordinação à ordem internacional.

Ambos os reducionismos, do direito à política (decisão) e da política ao direito (norma), não parecem adequados para lidar com a ligação que se pretende estabelecer entre a teoria da soberania e a edificação das fronteiras do edifício jurídico. Primeiro, porque não conseguem eliminar a tensão irredutível entre norma e decisão, entre supremacia da ordem internacional e da ordem interna, dada a natureza aporética da relação entre a soberania estatal e as demandas do sistema de estados (que tornam possível a reivindicação da soberania). Segundo, porque ambas as construções teóricas possuem como corolário necessário a demarcação das fronteiras entre o direito interno e o universo jurídico para além do Estado, reconhecendo a existência no interior do Estado territorial de uma ordem jurídica vigente dotada de unidade sistemática, já que se lhe investe de "um mesmo ponto final de imputação de todas as regras como uma força única concêntrica no sistema"28.

Confrontado com a dificuldade contemporânea de lidar com a questão em torno da unidade normativa do sistema jurídico em meio à existência de múltiplas

defendida segundo a qual é indispensável que seja reconhecida a imprescindibilidade de um principium unitatis que funcione como ponto de imputação de validade de todo o sistema. (SOLON, Ari Marcelo. Teoria da soberania como problema da norma jurídica e da decisão. p. 200). De acordo com as ideiais aqui defendidas, a redução interpretativa a uma única autoridade não se compraz com os desafios apresentados sobre o direito e sobre a constituição, sumarizados nos capítulos terceiro e quarto.

28 SOLON, Ari Marcelo. Teoria da soberania como problema da norma jurídica e da decisão. p. 200. 
fontes normativas não estruturadas hierarquicamente, Ari Solon indica que uma teoria da soberania ante tais desafios, ainda assim, não pode prescindir de um principium unitatis do sistema, devendo reconhecer "o fato da unidade do direito preservar na diversidade da experiência jurídica e na heterogeneidade de suas fontes" a sua "identidade formal"29.

Tem-se, portanto, uma das ideias centrais do papel da constituição em sua relação com a soberania: a consagração da ideia estruturante de unidade sistemática, ou mesmo de hierarquia normativa, como sendo o traço distintivo do direito nacional e o elemento caracterizador da natureza soberana do sistema de normas por ele veiculado. No entanto, há um sem-número de desafios contemporâneos que concorrem para uma desestruturação do modo de organização política próprio do estado territorial, ou, talvez, pelo menos, para a necessidade de rearticulação interna na forma como se inter-relacionam seus elementos constitutivos.

\section{CONSIDERAÇÕES FINAIS}

A título de esforço conclusivo, pode-se compreender que o modelo de estado territorial soberano funda-se na ideia de que as questões relativas à justa ordenação das relações sociais são suscitadas e respondidas somente no interior dos estados soberanos e, em menor medida, entre estados soberanos com territórios, populações e governos (comunidades políticas) mutuamente excludentes.

Asquestões relativas àjusta ordenação social envolvem os aspectos relacionados à justa representação, à justa distribuição de bens, ao justo reconhecimento e ao justo tratamento, sendo discursivamente veiculadas por meio de regras

29 "Se todo aglomerado de decisões puder ser atribuído a uma autoridade suprema no vértice de um processo dinâmico que, metaforicamente, é a vontade do Estado, mas, na realidade, abstraindo-se todo elemento pessoal e psicológico, é a última regra de imputação normativa. [...] Enquanto a aglomeração de normas, que podem até apresentar conflitos, puder ser reconduzida a 'um mesmo ponto final', encontramo-nos diante da continuidade formal do direito; o sistema é soberano, mesmo diante de cadeias normativas sofrendo rupturas contínuas. Se há descontinuidade, a unidade deixa de estar assegurada, se a norma-origem constituída por uma decisão fundamental sobre a forma da produção e variação das demais normas for violada por vias não previstas no próprio sistema. Nesse caso, não se está mais diante do mesmo sistema normativo, mas de outra ordem jurídica." (SOLON, Ari Marcelo.

Teoria da soberania como problema da norma jurídica e da decisão. p. 201). 
jurídicas fixadas de forma convencional, sobretudo pelo Estado. Estas normas são sistematicamente concebidas como ordens normativas estruturadas e produzidas em âmbitos de validade diferenciados: no plano interno, com base no direito constitucional estatal (direito nacional); no plano externo, com base no direito internacional (direito dos Estados nacionais).

Assim, no âmbito interno, a constituição permite a demarcação das fronteiras da ordem jurídica nacional, posto que, na qualidade de centro de imputação de autoridade normativa (estatal), possibilita sua estruturação mediante o encadeamento hierarquizado de centros emissores de ordens normativas (corporificado no modelo piramidal de Kelsen). A compreensão sistemática do direito permite a inferência, como traços constitutivos do ordenamento jurídico (nacional), dos postulados da unidade, da completude e da coerência sistêmica.

A partir destas premissas, é possível realizar um esforço de identificação do nascimento da teoria constitucional à consagração de pelo menos duas funções a serem atribuíveis à constituição: as funções de organização do poder e das liberdades (constitutição como fator de integridade) e de valoração do exercício do poder (constituição como fator de integração).

Contemporaneamente, constata-se que a constituição (nacional) vê-se confrontada por inúmeros desafios que colocam em xeque sua normatividade e o papel por si desempenhado.

Em relação ao acoplamento entre território e autoridade (base estruturante do modelo de "estado territorial soberano"), encontra-se em marcha um processo progressivo de desvinculação entre estes elementos no âmbito dos Estados. Este desacoplamento é tamanho que os Estados, segundo James Caporaso, veem diminuída sua capacidade de resistência à autoridade externa; não se trata de mera influência política, mas da impossibilidade concreta de que as instituições nacionais possam reverter a autoridade da ordenação produzida fora do Estado ${ }^{30}$.

30 James Caporaso chega a sustentar que as fronteiras territoriais e as estruturas de autoridade domésticas têm sofrido um processo crescente de desaclopamento; que as autoridades externas rotineiramente invadem o espaço reservado ao ordenamento jurídico dos estados nacionais (em especial, nos processos de integração regional); que o aparato decisório das instituições nacionais vem sendo "ameaçado" por práticas de instituições supranacionais, em especial, por meio de mecanismos de judicial review que subvertem, dramaticamente, 
Por conseguinte, o que se vislumbra é uma crescente impossibilidade de se "excluir a autoridade externa".

Estes diferentes processos conduzem ao que tem se convencionado denominar de insurgência de um espaço de transnacionalização do universo jurídico no curso do qual as estruturas de autoridade da ordem jurídica doméstica são colocadas em xeque por estruturas de autoridade de outros níveis não estatais.

O que está em questão, portanto, não é exatamente a criação de um Estado cosmopolita ou global, mas um entrelaçamento de relações entre autoridades domésticas e externas e uma predisposição de aceitação de uma ou outra autoridade de acordo com a natureza do problema que se tem a mão.

Estas tensões deságuam no debate em torno do lugar da constituição nos discursos de legitimação do direito e se materializam em esforços de desterritorialização da noção de constituição e do deslocamento de sua ideiamotriz (de ordenação social) para outros espaços de regulação não estatais.

A porosidade das fronteiras geográficas e a construção de novas fronteiras simbólicas não estruturadas em termos territoriais revelam a existência de processos não coordenados e parcialmente sobrepostos que exigem uma reinvenção dos modelos teóricos de organização da política e do direito. Tais processos concorrem para a perda da centralidade da ideia de territorialidade e para o desenvolvimento de modelos de compreensão da soberania em termos de compartilhamento.

Apesar dos desafios sumarizados, defende-se que as funções de organização e de valoração modernamente atribuídas à constituição (consubstanciadas aqui nas expressões constituição como fator de integridade e de integração da comunidade política) permanecem operativas desde que os múltiplos discursos sobre a constituição sejam formulados em estreita preocupação com a preservação das diferenças. Trata-se, pois, de compromisso que se traduz na formação de redes sobrepostas de interação e na necessidade de ampliação dos mecanismos de diálogo institucional entre diferentes atores (sobretudo, aqueles situados fora do Estado).

a ideia de capacidade última de decidir reconhecida, pelo Sistema de Vestfália, aos Estados soberanos. 
Lidar com estes mecanismos de diálogo e de interação é um dos principais desafios que se apresentam à compreensão do papel a ser desempenhado pela constituição, cuja "força" não se assenta sobre a noção de soberania estatal (autoridade), mas na capacidade de produzir acordos substantivos sobre as expectativas acerca da "justa ordenação" (legitimidade).

\section{REFERÊNCIAS}

BEAULAC, Stéphane. The Westphalian model in defining international law: challenging the myth. Australian Journal of Legal History, v. 8, n. 2, p. 181-213, 2004.

BLANEY, David; INAYATULLAH, Naeem. The Westphalian deferral. In: CAPORASO, J (Org.). Continuity and change in the Westphalian order. Malden, USA; Oxford, UK: Blackwell Publishers, 2000. p. 29-64.

CAPORASO, James. Changes in the Westphalian order: territory, public authority, and sovereignity. In: (Org.). Continuity and change in the Westphalian order. Malden, USA; Oxford, UK: Blackwell Publishers, 2000. p. 1-28.

CASELLA, Paulo Borba [2009]. Direito internacional dos espaços. São Paulo: Atlas, 2009.

CUTTITTA, Paolo. Points and lines: a topography of borders in global space. Ephemera: theory and politics in organization. v. 6, n. 1, p. 27-39, 2006.

ESTEVES, Paulo. Para uma genealogia do Estado territorial soberano. Revista de Sociologia e Política, Curitiba, n. 27, p. 15-32, nov. 2006.

GOYARD-FABRE, Simone [1999]. Os princípios filosóficos do direito político moderno. São Paulo: Martins Fontes, 1999.

KELSEN, Hans. O Estado como integração. São Paulo: Martins Fontes, 2003.

KELSEN, Hans. Teoria pura do direito. 6.ed. São Paulo: Martins Fontes, 1998.

KRASNER, Stephan. Sharing sovereignty: new institutions for collapsed and failing states. International security, v. 29, n. 2, p. 85-120, fall 2004.

LITFIN, Karen T. Sovereignty in world ecopolitics. Mershon International Studies Review, The International Studies Association, v. 41, n. 2, p. 167-204, nov. 1997. 
MACCORMICK, Neil. Questioning sovereignty: law, state, and practical reason. Oxford: Oxford University Press, 1999.

MESQUITA, Bruce Bueno de. Popes, kings, and endogenous institutions: the Concordat of Worms and the origins of sovereignty. In: CAPORASO, J. (Org.). Continuity and change in the Westphalian order. Malden, USA; Oxford, UK: Blackwell Publishers, 2000. p. 93-118.

PHILPOT, Daniel. Revolutions in sovereignty: how ideas shapped modern international relations. Princenton, Princenton University Press, 2001.

RUDOLPH, Christopher. Sovereignty and territorial borders in a global age. The International Studies Review, Malden; Oxford, Blackwell Publishers, v. 7, n. 1, p. 1-20, 2005.

RUGGIE, John Gerard. Territoriality and beyond: problematizing modernity in international relations. International organization, Cambridge Journals, v. 47, n. 1, p. 139-174, Winter, 1993.

SCHMITT, Carl. Teologia política. Belo Horizonte: Del Rey, 2006.

SCHMITT, Carl. Teoría de la constitución. Trad. Francisco Ayala. México: Editora Nacional, 1970.

SMEND, Rudolf. Constitución y derecho constitucional. Madrid: Centro de Estudios Constitucionales, 1985.

SOLON, Ari Marcelo. Teoria da soberania como problema da norma jurídica e da decisão. Porto Alegre: SAFE, 1997.

SPRUYT, Henrik. The sovereignty state and its competitors. Princeton: Princeton University Press, 1994.

WALKER, Rob. The double outside of the modern international. Ephemera: theory and politics in organization. v. 6, n. 1, p. 56-69, 2006. 